\title{
Early depressive symptoms after stroke: neuropsychological correlates and lesion characteristics
}

\author{
G.M.S. Nys ${ }^{\mathrm{a}, \mathrm{b}, *}$, M.J.E. van Zandvoort ${ }^{\mathrm{a}, \mathrm{b}}$, H.B. van der Worp ${ }^{\mathrm{b}}$, \\ E.H.F. de Haan ${ }^{\mathrm{a}, \mathrm{b}}$, P.L.M. de Kort ${ }^{\mathrm{c}}$, L.J. Kappelle \\ ${ }^{a}$ Psychological Laboratory, Helmholtz Instituut, Utrecht University, 3584 CS, The Netherlands \\ ${ }^{\mathrm{b}}$ Department of Neurology, University Medical Centre Utrecht, The Netherlands \\ ${ }^{\mathrm{c}}$ Department of Neurology, St. Elisabeth and Tweesteden Hospital Tilburg, The Netherlands
}

Received 21 May 2004; received in revised form 9 September 2004; accepted 10 September 2004

\begin{abstract}
Objective: To examine the relation between depressive symptoms and specific cognitive functions in patients with a recent stroke and to examine associations with lesion characteristics.

Methods: We studied 126 of 183 consecutive patients within 3 weeks after a first-ever symptomatic stroke (mean interval, $8.3 \pm 4.3$ days). Presence and severity of depressive symptoms was assessed with the Montgomery Åsberg Depression Rating Scale. Neuropsychological functioning was examined by means of a detailed neuropsychological examination covering six cognitive domains. We included a healthy control group $(N=75)$ to obtain normative data for the neuropsychological examination. Functional impairment was measured with the modified Barthel Index and the modified Rankin Scale. Symptomatic and preexistent lesion characteristics were determined on CT or MRI. Results: Of the included patients, $40 \%$ demonstrated mild and $12 \%$ moderate to severe depressive symptoms. Severity of depressive symptoms was related to lesion volume $(p=0.008)$, functional impairment (all $p<0.004)$, and degree of overall cognitive impairment $(p=0.005)$. After adjustment for lesion size, a specific neuropsychological profile emerged in patients with moderate to severe depressive symptoms, affecting primarily memory, visual perception, and language (all $p<0.05$ ). No association was found between severity of depressive symptoms and lesion location, presence of preexistent lesions (white matter lesions and silent infarcts), and demographic factors (age, education, and gender).

Conclusions: Moderate or severe symptoms of depression in the early stage poststroke are associated with a specific pattern of cognitive impairment, lesion size, and functional status. We suggest that depressive symptoms early after stroke are, at least in part, a reactive phenomenon secondary to severe cognitive and functional deficits.
\end{abstract}

(C) 2004 Elsevier B.V. All rights reserved.

Keywords: Depression; Cognition; Imaging; Stroke

\section{Introduction}

In the first weeks following stroke, the reported prevalence of depression varies from $9 \%$ to $37 \%$ [1-5]. Given this high prevalence and the negative impact of poststroke depression (PSD) on case fatality [1], functional

* Corresponding author. Psychological Laboratory, Helmholtz Instituut, Utrecht University, 3584 CS, The Netherlands. Tel.: +31 30 2533505; fax: +31302534511

E-mail address: g.nys@fss.uu.nl (G.M.S. Nys). outcome $[4,6,7]$, and rehabilitation [1,8], several studies have tried to identify patients who are most at risk for developing depression in the early phase after stroke. One of the most debated questions regarding PSD concerns the role of lesion location. Acute depression has been associated with left anterior lesions or lesions in the underlying basal ganglia $[2,4,5,9,10]$, but more recent studies were unable to replicate these results [3,11-13]. Lesion size has been associated with early PSD in a single study [2] but not in others $[4,10]$. Vascular risk factors [14,15], white matter lesions [16-18], and silent infarcts [19] have been related to 
depression in elderly people without a history of stroke, but studies of early depression in stroke patients have not considered these factors.

In contrast, the association between depression and global cognitive deterioration has been extensively demonstrated in stroke patients [5,20-22]. However, information about specific neuropsychological correlates is lacking. To date, only one study has reported a specific association between poor verbal abilities and depression in the first weeks poststroke [3]. Conceivably, other cognitive impairments could also be detected with a more detailed neuropsychological examination.

The aim of the present study was to characterize the neuropsychological profile of patients with depressive symptoms in the early phase of stroke and to examine the relation with characteristics of the acute brain lesion and the presence of older ischaemic lesions.

\section{Methods}

\subsection{Subjects}

\subsubsection{Patients}

The study population consisted of 183 consecutive patients with first-ever symptomatic stroke admitted to stroke units of three hospitals in The Netherlands (University Medical Centre Utrecht, Tweesteden Hospital Tilburg, and St. Elisabeth Hospital Tilburg) between February 2002 and January 2003. Only patients with ischaemic stroke or primary intracerebral haemorrhage were included. Diagnosis of stroke was based on both the presence of acute neurological symptoms and a compatible lesion on CT or MRI scans. Patients with a normal scan underwent a second scan within the first-weeks poststroke. Patients without evidence of a visible infarct or haemorrhage on the second scan, including those with a transient ischaemic attack, were excluded $(N=15)$. In order to minimize the influence of preexistent impairments on cognitive performance, we excluded patients with previous depression $(N=4)$, history of alcoholism or drug abuse $(N=3)$, preexistent dependence in activities of daily living (ADL; $N=2$ ), preexistent cognitive decline [as defined by a score of 3.6 or higher on the short Informant Questionnaire on cognitive decline in the elderly (IQCODE) Dutch version] [23] $(N=5)$, and patients older than 85 years $(N=2)$. Inasmuch as we were interested in symptoms of depression in the early phase after stroke, we included only patients who could be examined within 21 days of poststroke. This procedure resulted in the exclusion of patients with severe disturbances in consciousness $(N=12)$ and patients unable to communicate because of global aphasia $(N=10)$ lasting longer than 21 days. Four patients refused participation. This resulted in a population of 126 first-ever symptomatic stroke patients.

\subsubsection{Controls}

A healthy control group was studied $(N=87)$ to obtain normative data for the neuropsychological examination. The control group was closely matched to the patient group with respect to age, gender, and education. The controls were either spouses or family of patients or volunteers who came to our attention through advertising in newspapers or by word of mouth. Control subjects with signs of depression [either Montgomery Åsberg Depression Rating Scale (MADRS) $\geq 8$ or a history of depression $(N=5)]$, preexistent cognitive decline [as defined by a score of 3.6 or higher on the short Informant Questionnaire on cognitive decline in the elderly (IQCODE) Dutch version] [23] $(N=3)$, or a history of neurological illnesses $(N=4)$ were excluded from this study. This resulted in a population of 75 healthy controls.

The Ethics Committee of each participating hospital approved the study protocol. Written informed consent was obtained from each subject.

\subsection{Methods}

Presence and severity of depressive symptoms was rated by means of the Montgomery Åsberg Depression Rating Scale (MADRS) [24]. This observer-rated scale is a 10-item scale ranging from $0-60$ and puts little emphasis on somatic symptoms. Therefore, it has often been used in elderly patients and patients with stroke [25-28].

All patients received a detailed neuropsychological examination covering the six major cognitive domains. Each domain was composed of at least two neuropsychological tasks resulting in the following test battery [29]: (1) reasoning [Raven Advanced Progressive Matrices (short form) and Similarities (WAIS-III)], (2) memory (Rey Auditory Verbal Learning Test and Rey-Osterrieth Complex Figure-Delay), (3) executive functioning [Brixton Spatial Anticipation Test [30], Visual Elevator [31] (Test of Everyday Attention), and letter fluency], (4) visuoperception [Judgement of Line Orientation (short form), Test of Facial Recognition (short form), Rey-Osterrieth Complex Figure-Copy], (5) attention [Digit Span (WAIS-III), Corsi Block span, Star Cancellation (Behavioural Inattention Test)], (6) language [Token test (short form) and Boston Naming Test (short form)]. We used the number of impaired cognitive domains $(0-6)$ to represent overall cognitive performance.

Functional status was evaluated with the modified Barthel Index [32]. This is a commonly used basic ADL checklist ranging from 0 (completely dependent) to 20 (completely independent). Handicap was rated with the modified Rankin Scale [33] ranging from 0 (no symptoms) to 5 (severe disability). Both functional measurements were performed on the same day as the neuropsychological examination.

Lesion characteristics were determined from CT $(N=65)$ or MRI $(N=61)$ by an experienced stroke neurologist 
(HBvdW) who was blind for the clinical data. Lesions were classified by territory of arterial blood supply (classified as anterior, middle, posterior, vertebral, or basilar artery) and involvement of supra- (left, right, and bilateral) or infratentorial (brain stem or cerebellum) areas. Supratentorial stroke lesions were further dichotomised into (1) purely subcortical and (2) combined cortical and subcortical lesions. Moreover, involvement of the caudate nucleus, internal capsule, basal ganglia, and thalamus was rated as absent or present. Silent infarcts were classified as present when an infarct was found in the brain without the description by the patient, family, or medical record of a prior stroke event. The extent of white matter lesions was classified as follows: 0 -no white matter lesions, 1 -minor white matter lesions, 2 -moderate white matter lesions, 3 confluent white matter lesions [34]. Lesion volume was calculated with Leica Q500 MCP image analysis software by manual tracing of the lesion on each slice showing the infarct or haemorrhage. This method has been shown to have a high interrater reliability and is described in detail elsewhere [35].

\subsection{Statistical analyses}

Patients were classified into three categories based on the level of depressive symptoms (absent, mild, and moderate to severe) according to standardized cutoff scores on the MADRS [36]. Between-group comparisons were made by using chi-square analyses for nominal data, Kruskall-Wallis $H$ tests for ordinal data and univariate analyses of variance (ANOVA) for continuous data. Post hoc Scheffé comparison tests were undertaken for further analysis of significant ANOVAs.

Patients' neuropsychological test results were standardized into $z$ scores based on the means and standard deviations (S.D.) of the control group. It should be noted here that no difference emerged between spouses or family of patients and the community volunteers in our control sample with respect to cognitive function. Performance was categorized as cognitive impairment if $z$ scores of patients fell below -1.5 [31]. Domain scores were calculated by averaging $z$ scores of tasks contributing to the specific domains and compared between patient groups. All tests were two-tailed, with results considered significant at $p<0.05$.

\section{Results}

Of the patients included, $48 \%$ had no depressive symptoms (MADRS $<8$ ), 40\% had mild depressive symptoms (MADRS 8-19), and 12\% had moderate to severe depressive symptoms (MADRS $>19$ ). Patients' demographic and functional characteristics are presented in Table 1. The three groups did not differ with respect to age, education, gender, or days between stroke onset and the examination.
Table 1

Patients' characteristics classified by severity of depressive symptoms

\begin{tabular}{|c|c|c|c|c|c|}
\hline & \multirow{2}{*}{$\frac{\text { Overall }}{N=126}$} & \multicolumn{4}{|c|}{ Depressive symptoms } \\
\hline & & $\begin{array}{l}\text { Absent } \\
(N=60)\end{array}$ & $\begin{array}{l}\text { Mild } \\
(N=51)\end{array}$ & $\begin{array}{l}\text { Mod./sev. } \\
(N=15)\end{array}$ & $P$ \\
\hline \multicolumn{6}{|l|}{ Age } \\
\hline Mean (S.D.) & $\begin{array}{l}62.3 \\
(13.3)\end{array}$ & $\begin{array}{l}61.9 \\
(12.5)\end{array}$ & $\begin{array}{l}62.0 \\
(14.7)\end{array}$ & $\begin{array}{l}65.1 \\
(11.9)\end{array}$ & $0.70^{\mathrm{a}}$ \\
\hline \multicolumn{6}{|l|}{ Education $^{b}$} \\
\hline Median (range) & $\begin{array}{l}4.0 \\
(1-7)\end{array}$ & $\begin{array}{l}4.0 \\
(1-7)\end{array}$ & $\begin{array}{l}4.0 \\
(1-7)\end{array}$ & $\begin{array}{l}4.0 \\
(2-6)\end{array}$ & $0.47^{\mathrm{c}}$ \\
\hline $\begin{array}{l}\text { Male gender } \\
\%\end{array}$ & 46.8 & 48.3 & 49.0 & 33.3 & $0.54^{\mathrm{d}}$ \\
\hline $\begin{array}{l}\text { Interval between } \\
\text { stroke and } \\
\text { examination } \\
\text { (days) }\end{array}$ & & & & & \\
\hline Mean (S.D.) & $\begin{array}{l}8.3 \\
(4.3)\end{array}$ & $\begin{array}{l}7.8 \\
(4.4)\end{array}$ & $\begin{array}{l}8.7 \\
(4.6)\end{array}$ & $\begin{array}{l}8.9 \\
(2.7)\end{array}$ & $0.46^{\mathrm{a}}$ \\
\hline $\begin{array}{l}\text { Modified Barthel } \\
\text { Index }\end{array}$ & & & & & \\
\hline Median (range) & $\begin{array}{l}17.0 \\
(2-20)\end{array}$ & $\begin{array}{l}18.0 \\
(5-20)\end{array}$ & $\begin{array}{l}18.0 \\
(2-20)\end{array}$ & $\begin{array}{l}9.0 \\
(2-18)\end{array}$ & $0.003^{\mathrm{c}}$ \\
\hline $\begin{array}{l}\text { Modified Rankin } \\
\text { Scale }\end{array}$ & & & & & \\
\hline Median (range) & $\begin{array}{l}3.0 \\
(1-5)\end{array}$ & $\begin{array}{l}3.0 \\
(1-4)\end{array}$ & $\begin{array}{l}2.0 \\
(1-5)\end{array}$ & $\begin{array}{l}4.0 \\
(2-5)\end{array}$ & $0.004^{\mathrm{c}}$ \\
\hline
\end{tabular}

S.D. - standard deviation, Mod./sev.-moderate to severe.

a By univariate ANOVA.

b Education level is scored using seven categories. 1-not finished primary school, 7-university degree [37]

c By Kruskall-Wallis test.

d By $\chi 2$ test.

Patients with moderate to severe depressive symptoms were more physically dependent and had a more severe handicap than patients with no or mild depressive symptoms. During their hospital stay, 10 of $126(8 \%)$ patients received antidepressant medication. Three of these patients demonstrated no depressive symptoms on the MADRS, five patients showed mild symptoms, and three patients showed moderate to severe symptoms.

Lesion characteristics were similar in patients investigated by CT or MRI. Therefore, further analysis was carried out on the group as a whole. Table 2 shows an overview of lesion characteristics for the entire group and for each of the three categories of depressive symptoms. A large main effect of lesion volume on severity of depressive symptoms was found between groups $[F(2,124)=5.062$, $p=0.008]$. Post hoc Scheffé analysis revealed that patients with moderate to severe depressive symptoms had a larger lesion volume than patients with no depressive symptoms ( $p=0.008)$ or patients with mild depressive symptoms $(p=0.05)$. No association could be demonstrated between severity of depressive symptoms and lesion location, territory of arterial blood supply, presence of silent infarct(s), and extent of white matter lesions. No differences between groups were found in involvement of subcortical structures (Table 3). 
Table 2

Lesion characteristics classified by severity of depressive symptoms

\begin{tabular}{|c|c|c|c|c|c|c|c|c|}
\hline & \multicolumn{2}{|l|}{$\underline{\text { Overall }}$} & \multicolumn{6}{|c|}{ Depressive symptoms } \\
\hline & \multirow[t]{2}{*}{$N=126$} & \multirow[t]{2}{*}{$\%$} & \multicolumn{2}{|l|}{ None } & \multicolumn{2}{|l|}{ Mild } & \multicolumn{2}{|l|}{ Mod./sev. } \\
\hline & & & $N=60$ & $\%$ & $N=51$ & $\%$ & $N=51$ & $\%$ \\
\hline \multicolumn{9}{|l|}{ Type of stroke } \\
\hline Infarct & $111 / 126$ & $88.1 \%$ & $55 / 60$ & $91.7 \%$ & $42 / 51$ & $82.4 \%$ & $14 / 15$ & $93.3 \%$ \\
\hline Haemorrhage & $15 / 126$ & $11.9 \%$ & $5 / 60$ & $8.3 \%$ & $9 / 51$ & $17.6 \%$ & $1 / 15$ & $6.7 \%$ \\
\hline \multicolumn{9}{|l|}{ Lesion location } \\
\hline \multicolumn{9}{|l|}{ Supratentorial } \\
\hline Left & $53 / 126$ & $42.1 \%$ & $28 / 60$ & $46.7 \%$ & $19 / 51$ & $37.3 \%$ & $6 / 15$ & $40.0 \%$ \\
\hline Right & $50 / 126$ & $39.7 \%$ & $17 / 60$ & $28.3 \%$ & $26 / 51$ & $51.0 \%$ & $7 / 15$ & $46.7 \%$ \\
\hline Bilateral & $4 / 126$ & $3.2 \%$ & $3 / 60$ & $5.0 \%$ & $1 / 51$ & $2.0 \%$ & $0 / 15$ & $0.0 \%$ \\
\hline \multicolumn{9}{|l|}{ Infratentorial } \\
\hline Brain stem & $9 / 126$ & $7.1 \%$ & $6 / 60$ & $10.0 \%$ & $3 / 51$ & $5.9 \%$ & $0 / 15$ & $0.0 \%$ \\
\hline Cerebellum & $10 / 126$ & $7.9 \%$ & $6 / 60$ & $10.0 \%$ & $2 / 51$ & $3.9 \%$ & $2 / 15$ & $13.3 \%$ \\
\hline \multicolumn{9}{|l|}{ Supratentorial lesions } \\
\hline Cortical/subcortical & $49 / 107$ & $45.8 \%$ & $18 / 48$ & $37.5 \%$ & $22 / 46$ & $47.8 \%$ & $9 / 13$ & $69.2 \%$ \\
\hline Subcortical & $58 / 107$ & $30.8 \%$ & $30 / 48$ & $62.5 \%$ & $24 / 46$ & $52.2 \%$ & $4 / 13$ & $30.8 \%$ \\
\hline \multicolumn{9}{|c|}{ Territory of arterial supply } \\
\hline Anterior c.a. & $3 / 126$ & $2.4 \%$ & $1 / 60$ & $1.7 \%$ & $1 / 51$ & $2.0 \%$ & $1 / 15$ & $6.7 \%$ \\
\hline Middle c.a. & $77 / 126$ & $61.1 \%$ & $38 / 60$ & $63.3 \%$ & $29 / 51$ & $65.9 \%$ & $10 / 15$ & $66.7 \%$ \\
\hline Posterior c.a. & $26 / 126$ & $20.6 \%$ & $8 / 60$ & $13.3 \%$ & $16 / 51$ & $31.4 \%$ & $2 / 15$ & $13.3 \%$ \\
\hline Vertebral a. & $11 / 126$ & $8.7 \%$ & $7 / 60$ & $11.7 \%$ & $2 / 51$ & $3.9 \%$ & $2 / 15$ & $13.3 \%$ \\
\hline Basilar a. & $9 / 126$ & $7.1 \%$ & $6 / 60$ & $10.0 \%$ & $3 / 51$ & $5.9 \%$ & $0 / 15$ & $0.0 \%$ \\
\hline \multicolumn{9}{|l|}{ Lesion volume, $\mathrm{cm}^{3}$} \\
\hline Mean \pm S.D.* & $16.5 \pm 27.3$ & & $11.6 \pm 24.7$ & & $16.7 \pm 27.5$ & & $35.8 \pm 29.7$ & \\
\hline Silent infarction & $25 / 126$ & $19.8 \%$ & $16 / 60$ & $26.7 \%$ & $8 / 51$ & $15.7 \%$ & $1 / 15$ & $6.7 \%$ \\
\hline \multicolumn{9}{|l|}{ Leukoaraiosis } \\
\hline Absent & $96 / 126$ & $76.2 \%$ & $43 / 60$ & $71.7 \%$ & $40 / 51$ & $78.4 \%$ & $13 / 15$ & $86.7 \%$ \\
\hline Mild & $17 / 126$ & $13.5 \%$ & $11 / 60$ & $18.3 \%$ & $4 / 51$ & $7.8 \%$ & $2 / 15$ & $13.3 \%$ \\
\hline Moderate & $10 / 126$ & $7.9 \%$ & $4 / 60$ & $6.7 \%$ & $6 / 51$ & $11.8 \%$ & $0 / 15$ & $0.0 \%$ \\
\hline Confluents & $3 / 126$ & $2.4 \%$ & $2 / 60$ & $3.3 \%$ & $1 / 51$ & $2.0 \%$ & $0 / 15$ & $0.0 \%$ \\
\hline
\end{tabular}

Values are frequencies (within-group percentages). Mod./sev.—moderate to severe; c.a. — cerebral artery; S.D.- standard deviation. ${ }^{*} p<0.01$.

A significant relationship was found between the severity of depressive symptoms and overall cognitive function, that is, patients with moderate to severe depressive symptoms demonstrated three times more cognitive impairments than patients with no or mild depressive symptoms $\left[\chi^{2}(2)=10.4\right.$, $p=0.005]$. Subsequently, we assessed whether differences in neuropsychological profiles could be demonstrated between groups. An ANCOVA was performed to correct for the difference in lesion size between groups. Fig. 1 shows mean cognitive domain scores for each group. Between-group differences were found in memory $[F(2,122)=4.08$, $p=0.019]$, visuoperception $[F(2,122)=4.64, p=0.012]$, and language $[F(2,122)=3.26, p=0.042]$. Further analyses indi- cated that patients with moderate or severe depressive symptoms performed significantly worse than the other patient groups $(p<0.05)$. Patients with mild depressive symptoms showed the same performance as patients without depressive symptoms on all cognitive domains (all $p>0.05$ ).

\section{Discussion}

In the present study, we have demonstrated for the first time that stroke patients with early depressive symptoms show a specific neuropsychological profile, which is in contrast with earlier reports of a global cognitive

Table 3

Involvement of subcortical structures classified by severity of depressive symptoms

\begin{tabular}{|c|c|c|c|c|c|c|c|c|}
\hline & \multirow[t]{3}{*}{ Overall } & & \multicolumn{6}{|c|}{ Depressive symptoms } \\
\hline & & & \multicolumn{2}{|l|}{ None } & \multicolumn{2}{|l|}{ Mild } & \multicolumn{2}{|c|}{ Mod./sev. } \\
\hline & & & $N=60$ & $\%$ & $N=51$ & $\%$ & $N=15$ & $\%$ \\
\hline Caudate nucleus & $11 / 126$ & $8.7 \%$ & $4 / 60$ & $6.7 \%$ & $5 / 51$ & $9.8 \%$ & $2 / 15$ & $13.3 \%$ \\
\hline Basal ganglia & $27 / 126$ & $21.4 \%$ & $10 / 60$ & $16.7 \%$ & $12 / 51$ & $23.5 \%$ & $5 / 15$ & $33.3 \%$ \\
\hline Thalamus & $17 / 126$ & $13.5 \%$ & $7 / 60$ & $11.7 \%$ & $8 / 51$ & $15.7 \%$ & $2 / 15$ & $13.3 \%$ \\
\hline Internal capsule & $34 / 126$ & $27.0 \%$ & $14 / 60$ & $23.3 \%$ & $15 / 51$ & $29.4 \%$ & $5 / 15$ & $33.3 \%$ \\
\hline
\end{tabular}

Values are frequencies (within-group percentages). Mod./sev.=moderate to severe. 


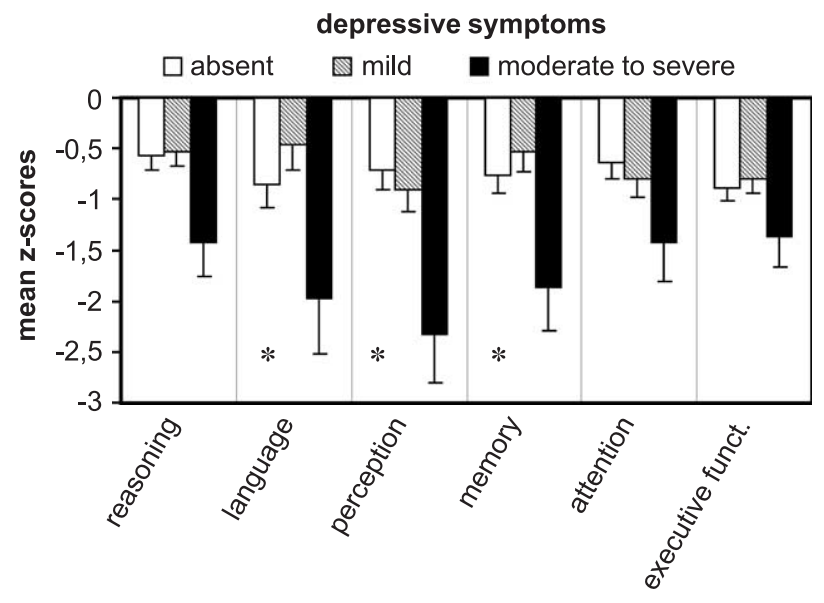

Fig. 1. Mean $z$ scores in each cognitive domain across patient groups. Error bars indicate standard errors.

deterioration [5,20,21,38]. Visuoperception, memory, and language were particularly affected in patients with moderate to severe depressive symptoms. Age, education, nor gender could account for these findings as these variables were not related to severity of depressive symptoms. Moreover, this pattern emerged after adjustment for the volume of the lesion. The most probable explanation for the selective neuropsychological profile in our patient sample is that aphasia, amnesia, and perceptual distortions are immediately apparent and disabling to patients in the early phase of stroke and that depressive symptoms are secondary to these impairments. In contrast, impairments in executive functioning, reasoning, and attention span are less noticeable in a structured environment, like the stroke unit. Alternatively, depression might evolve simultaneously with cognitive impairment following acute stroke. However, given the diverse nature of the cognitive impairments associated with depression severity in our study and the lack of a relationship with lesion location, this explanation seems less likely.

It has recently been suggested that the time elapsed since stroke onset is very important in distinguishing between directly related (biological) and reactive (psychological) forms of PSD [2]. Several studies have reported an association between depression and lesion characteristics in the very early phase poststroke, thus supporting the concept of biological depression $[2,4,5,9,10]$. More recent studies were not able to replicate these findings [3,11-13], for which reason some argue that PSD is always reactive in nature, independent of the interval since stroke onset $[12,39,40]$. This view is corroborated by a recent study demonstrating that depressive symptom profiles of patients with PSD in both acute and more chronic stages showed a psychological 'reactive' pattern, whereas depressed patients without a history of stroke demonstrated more biologically determined symptoms [12].

The present study sheds new light on this ongoing controversy. Neither lesion side nor lesion location was related to severity of depressive symptoms in the early phase of stroke. Furthermore, no association could be demonstrated with involvement of subcortical structures in the brain. The volume of the lesion was the only lesion characteristic associated with the severity of depressive symptoms in the first weeks poststroke. The neuropsychological profile found in the present study is different from what is usually reported in depressed patients without a history of stroke. Major depression in these patients typically results in impairments in concentration, memory encoding, psychomotor speed, and executive functioning [41,42], whereas our patients showed disproportionately poor language capacities, long-term memory failure, and perceptual distortions. This dissimilar pattern suggests that the underlying mechanisms of cognitive disorders in PSD and major (not stroke related) depression are different. Furthermore, in patients with major depression without a history of stroke, depression has been associated with white matter lesions [16-18], silent infarcts [19], and cardiovascular risk factors $[14,15]$. In contrast, our study shows that neither silent infarcts nor white matter lesions contribute to depressive symptoms in the early phase poststroke. Similarly, another study found that the extent of white matter lesions was unrelated to depression at more chronic stages of poststroke [43]. Altogether, these findings imply that depressive symptoms occurring in the early phase poststroke are, at least in part, a reactive manifestation to sudden and severe cognitive and functional impairment rather than a direct result of damage to specific brain regions.

Our study has the following strengths. First, this study has included a substantial number of patients, and it is among the few that examined patients in the very early phase poststroke. Second, instead of using a global cognitive screening instrument such as the Mini-Mental State Examination [44] or the R-CAMCOG [45], we examined patients with a detailed neuropsychological examination, which allowed evaluation of specific cognitive performance. Third, we chose to assess severity of depressive symptoms with the MADRS, an observer-rated measure that is easy to use in clinical practice, whereas a formal psychiatric assessment might not be feasible in some patients with cognitive or aphasic disturbances. Moreover, the MADRS has often been used in stroke patients [25-28] and puts little emphasis on somatic symptoms. This is important because some of the symptoms that are used to diagnose depression such as fatigue, pain, or sleeping disorders can be the direct result of the stroke itself [40]. Given that these somatic symptoms are common in the first weeks of stroke, we avoided categorizing patients by means of standard selfrating questionnaires or standard criteria.

Several limitations of our study should also be addressed. First, in order to maximize comparability between CT and MRI, simple methods for rating white 
matter lesions and silent infarcts were used. These methods are less detailed than volumetric methods. Moreover, given that the extent of subcortical but not periventricular white matter lesions has been related to depression in patients without a history of stroke [18], the location of white matter changes and silent infarcts might still be important in stroke patients. Second, in order to study neuropsychological correlates of early depressive symptoms and the relation with lesion characteristics, we excluded patients with preexistent cognitive dysfunction or depression. Presumably, these patients show more white matter lesions and silent infarcts than our patient population. Third, inasmuch as we were interested in the acute phase poststroke, patients with global aphasia and with severe disturbances of consciousness could not be included in this study.

In conclusion, the present study is the first to examine the relation between severity of depressive symptoms and detailed neuropsychological functioning in the very early phase after stroke. The presence of severe depressive symptoms in this early stage is associated with specific cognitive impairment, large lesion size, and poor functional status. These findings might contribute to the early identification of patients at risk for developing depression. We suggest that early depressive symptoms in stroke patients are, at least in part, a reactive phenomenon secondary to severe cognitive and functional deficits.

\section{Acknowledgements}

This study was supported by grant no. 2000.23 from the Netherlands Heart Foundation. We want to thank Dr. BPW Jansen for the enrollment of patients and Professor Dr. J. van Gijn for his useful comments on this manuscript. The data were presented at the 3rd International Congress on Vascular Dementia (Prague).

\section{References}

[1] Whyte EM, Mulsant BH. Post-stroke depression: epidemiology, pathophysiology, and biological treatment. Biol Psychiatry 2002;52: $253-64$.

[2] Shimoda K, Robinson RG. The relationship between poststroke depression and lesion location in long-term follow-up. Biol Psychiatry 1999;45:187-92.

[3] Berg A, Palomaki H, Lehtihalmes M, Lonnqvist J, Kaste M. Poststroke depression in acute phase after stroke. Cerebrovasc Dis 2001;12:14-20.

[4] Åström M, Adolfsson R, Asplund K. Major depression in stroke patients: a 3-year longitudinal study. Stroke 1993;24:976-82.

[5] Robinson RG, Starr LB, Kubos KL, Price TR. A two-year longitudinal study of post-stroke mood disorders: findings during the initial evaluation. Stroke 1983;14:736-41.

[6] Herrmann N, Black SE, Lawrence J, Szekely C, Szalai JP. The Sunnybrook Stroke Study: a prospective study of depressive symptoms and functional outcome. Stroke 1998;29:618-24.
[7] Parikh RM, Lipsey JR, Robinson RG, Price TR. Two-year longitudinal study of post-stroke mood disorders: dynamic changes in correlates of depression at one and two years. Stroke 1987;18:579-84.

[8] Gillen R, Tennen H, McKee TE, Gernert-Dott P, Affleck G. Depressive symptoms and history of depression predict rehabilitation efficiency in stroke patients. Arch Phys Med Rehabil 2001;82: $1645-9$.

[9] Herrmann M, Bartels C, Schumacher M, Wallesch CW. Poststroke depression. Is there a pathoanatomic correlate for depression in the postacute stage of stroke? Stroke 1995;26:850-6.

[10] Robinson RG, Starr LB, Lipsey JR, Rao K, Price TR. A two-year longitudinal study of post-stroke mood disorders: dynamic changes in associated variables over the first six months of follow-up. Stroke 1984;15:510-7.

[11] Carson AJ, MacHale S, Allen K, Lawrie SM, Dennis M, House A, et al. Depression after stroke and lesion location: a systematic review. Lancet 2000;356:122-6.

[12] Gainotti G, Azzoni A, Marra C. Frequency, phenomenology and anatomical-clinical correlates of major post-stroke depression. Br J Psychiatry 1999; 175:163-7.

[13] Burvill PW, Johnson GA, Chakera TMH, StewartWynne EG, Anderson CS, Jamrozik KD. The place of site of lesion in the aetiology of post-stroke depression. Cerebrovase Dis 1996;6:208-15.

[14] Alexopoulos GS. Vascular disease, depression, and dementia. J Am Geriatr Soc 2003;51:1178-80.

[15] Carney RM, Rich MW, Tevelde A, Saini J, Clark K, Jaffe AS. Major depressive disorder in coronary artery disease. Am J Cardiol 1987;60: $1273-5$.

[16] Taylor WD, Steffens DC, MacFall JR, McQuoid DR, Payne ME, Provenzale JM, et al. White matter hyperintensity progression and late-life depression outcomes. Arch Gen Psychiatry 2003;60:1090-6.

[17] Steffens DC, Krishnan KR, Crump C, Burke GL. Cerebrovascular disease and evolution of depressive symptoms in the cardiovascular health study. Stroke 2002;33:1636-44.

[18] de Groot JC, de Leeuw FE, Oudkerk M, Hofman A, Jolles J, Breteler MM. Cerebral white matter lesions and depressive symptoms in elderly adults. Arch Gen Psychiatry 2000;57:1071-6.

[19] Fujikawa T, Yamawaki S, Touhouda Y. Incidence of silent cerebral infarction in patients with major depression. Stroke 1993;24:1631-4.

[20] Robinson RG, Bolla-Wilson K, Kaplan E, Lipsey JR, Price TR. Depression influences intellectual impairment in stroke patients. Br J Psychiatry 1986;148:541-7.

[21] Murata Y, Kimura M, Robinson RG. Does cognitive impairment cause post-stroke depression? Am J Geriatr Psychiatry 2000;8:310-7.

[22] Downhill Jr JE, Robinson RG. Longitudinal assessment of depression and cognitive impairment following stroke. J Nerv Ment Dis 1994; 182:425-31.

[23] de Jonghe JF, Schmand B, Ooms ME, Ribbe MW. Abbreviated form of the Informant Questionnaire on Cognitive Decline in the Elderly. Tijdschr Gerontol Geriatr 1997;28:224-9.

[24] Montgomery SA, Asberg M. A new depression scale designed to be sensitive to change. Br J Psychiatry 1979;134:382-9.

[25] Singh A, Black SE, Herrmann N, Leibovitch FS, Ebert PL, Lawrence $\mathrm{J}$, et al. Functional and neuroanatomic correlations in poststroke depression: the Sunnybrook Stroke Study. Stroke 2000;31:637-44.

[26] Suenkeler IH, Nowak M, Misselwitz B, Kugler C, Schreiber W, Oertel $\mathrm{WH}$, et al. Timecourse of health-related quality of life as determined 3, 6 and 12 months after stroke. Relationship to neurological deficit, disability and depression. J Neurol 2002;249:1160-7.

[27] Wiart L, Petit H, Joseph PA, Mazaux JM, Barat M. Fluoxetine in early poststroke depression: a double-blind placebo-controlled study. Stroke 2000;31:1829-32.

[28] Herrmann N, Black SE, Lawrence J, Szekely C, Szalai JP. The Sunnybrook Stroke Study: a prospective study of depressive symptoms and functional outcome. Stroke 1998;29:618-24.

[29] Lezak MD, editor. Neuropsychological assessment. New York, NY: Oxford University Press; 1995. 
[30] Burgess PW, Shallice T. The Hayling and Brixton tests. Thames Valley Test Company; 1997.

[31] Robertson IH, Ward T, Ridgeway V, Nimmo-Smith I. The test of everyday attention. Thames Valley Test; 1994.

[32] Mahoney FI, Barthel DW. Functional evaluation: the Barthel Index. Med State Med J 1965;14:61-5.

[33] van Swieten JC, Koudstaal PJ, Visser MC, Schouten HJ, van Gijn J. Interobserver agreement for the assessment of handicap in stroke patients. Stroke 1988;19:604-7.

[34] van Swieten JC, Hijdra A, Koudstaal PJ, van Gijn J. Grading white matter lesions on CT and MRI: a simple scale. J Neurol Neurosurg Psychiatry 1990;53:1080-3.

[35] van der Worp HB, Claus SP, Bar PR, Ramos LM, Algra A, van Gijn J, et al. Reproducibility of measurements of cerebral infarct volume on CT scans. Stroke 2001;32:424-30.

[36] Snaith RP, Harrop FM, Newby DA, Teale C. Grade scores of the Montgomery-Asberg depression and the clinical anxiety scales. Br J Psychiatry 1986;148:599-601.

[37] Hochstenbach J, Mulder T, van Limbeek J, Donders R, Schoonderwaldt H. Cognitive decline following stroke: a comprehensive study of cognitive decline following stroke. J Clin Exp Neuropsychol 1998;20:503-17.

[38] Kauhanen M, Korpelainen JT, Hiltunen P, Brusin E, Mononen H, Maatta R, et al. Post-stroke depression correlates with cognitive impairment and neurological deficits. Stroke 1999;30:1875-80.
[39] Gainotti G, Marra C. Determinants and consequences of post-stroke depression. Curr Opin Neurol 2002;15:85-9.

[40] Gainotti G, Azzoni A, Razzano C, Lanzillotta M, Marra C, Gasparini F. The Post-Stroke Depression Rating Scale: a test specifically devised to investigate affective disorders of stroke patients. J Clin Exp Neuropsychol 1997;19:340-56.

[41] Elderkin-Thompson V, Kumar A, Bilker WB, Dunkin JJ, Mintz J, Moberg PJ, et al. Neuropsychological deficits among patients with late-onset minor and major depression. Arch Clin Neuropsychol 2003; 18:529-49.

[42] Veiel HO. A preliminary profile of neuropsychological deficits associated with major depression. J Clin Exp Neuropsychol 1997; 19:587-603.

[43] Vataja R, Pohjasvaara T, Leppavuori A, Mantyla R, Aronen HJ, Salonen $\mathrm{O}$, et al. Magnetic resonance imaging correlates of depression after ischemic stroke. Arch Gen Psychiatry 2001;58:925-31.

[44] Folstein MF, Folstein SE, McHugh PR. "Mini-mental state". A practical method for grading the cognitive state of patients for the clinician. J Psychiatr Res 1975;12:189-98.

[45] de Koning I, Dippel DW, van Kooten F, Koudstaal PJ. A short screening instrument for poststroke dementia: the R-CAMCOG. Stroke 2000;31:1502-8. 